\title{
A bilobed groin flap for coverage of traumatic injury to both the volar and dorsal hand surfaces
}

\author{
Trevor M Brooks MSc, Abdulaziz T Jarman MD, Jaret L Olson MD
}

\author{
TM Brooks, AT Jarman, JL Olson. A bilobed groin flap for \\ coverage of traumatic injury to both the volar and dorsal hand \\ surfaces. Can J Plast Surg 2007;15(1):49-51.
}

BACKGROUND: There are many methods available for coverage
of both the volar and dorsal hand surfaces in traumatic injury. All of
these surgical procedures allow for ample coverage of the defect, but
have the major drawback of needing multiple donor sites. In the pres-
ent report, a case of a complex crush injury to the hand in which both
volar and dorsal surfaces received traumatic injury is presented. A
bilobed groin flap pedicled on the superficial circumflex iliac artery
was fashioned to cover the entire defect. Like many other described
flaps, the bilobed groin flap resulted in a favourable functional and
cosmetic result for the patient, but with the unique advantage of
requiring a single donor site. METHODS: A bipedicled groin flap was raised from distal to proximal, and the flaps inset onto both the dorsal and volar hand defects. RESULTS: The patient regained adequate function of his hand, and was able to return to work full-time as a manual labourer.

CONCLUSION: The bilobed groin flap appears to be a valuable option for covering complex hand injuries involving both the volar and dorsal surfaces of the hand.

Key Words: Bilobed; Crush injury; Groin flap; Pedicled; Tissue flap

\section{Lambeau bilobé inguinal pour la correction d'une blessure traumatique aux faces palmaire et dorsale de la main}

\begin{abstract}
HISTORIQUE : Plusieurs méthodes ont été mises au point pour recouvrir les faces palmaire et dorsale de la main après un traumatisme. Toutes ces techniques chirurgicales permettent une ample correction de la lésion, mais ont comme inconvénient majeur la nécessité de recourir à plusieurs sites donneurs. Le présent rapport fait état d'un cas complexe de blessure par écrasement avec atteinte des surfaces palmaire et dorsale de la main. Un lambeau bilobé inguinal a été façonné avec vascularisation à partir de l'artère iliaque circonflexe superficielle pour recouvrir l'ensemble de la lésion. Comme plusieurs autres lambeaux préalablement décrits, le lambeau inguinal bilobé a donné un résultat fonctionnel et cosmétique satisfaisant pour le patient, mais a pour avantage particulier de ne nécessiter qu'un seul site donneur.

MÉTHODE : Un lambeau inguinal bipédiculé a été soulevé de la portion distale à la proximale et les lambeaux ont été insérés sur les lésions des faces dorsale et palmaire de la main.

RÉSULTATS : Le patient a récupéré une fonction adéquate de sa main et il a pu reprendre son travail d'ouvrier manuel à temps complet.

CONCLUSION : Le lambeau inguinal bilobé semble une option utile pour recouvrir les lésions complexes de la main avec atteinte des faces palmaire et dorsale.
\end{abstract}

Since first described by McGregor and Jackson in 1972 (1), the groin flap has been widely used in the field of reconstructive surgery. Numerous surgical techniques that use the pedicled $(2,3)$ or free groin flap as a means of dealing with complex soft tissue injuries of the head and neck $(4,5)$, as well as the extremities $(3,5,6)$, have been described. The groin flap is an axial pattern flap based on the superficial circumflex iliac artery. This relatively constant vascular supply forms a cartwheel of anastomosing vessels that encompass a large area of the groin and hypogastrium, thereby allowing for a substantial amount of tissue to be utilized.

Concurrent defects of the dorsal and volar surfaces of the hand have long been a challenge to reconstructive hand surgeons. Several combinations of pedicled flaps to cover this defect have been reported in the literature (6-8). Bilobed groin flaps have been described as a means of correcting the hand in Apert syndrome (9), as well as to cover defects after contracture release of the thumb (10). However, we have been unable to find any cases in the literature of the bilobed pedicled groin flap being used to treat traumatic degloving injuries of the hand. Thus, we present a case outlining an alternate use for this versatile flap.

\section{CASE PRESENTATION}

A 35-year-old man sustained full-thickness skin loss of both the dorsal and volar aspects of his right hand as a result of an industrial accident. The initial treatment, at another institution, consisted of debridement of the wound and $\mathrm{K}$-wire fixation of the second through fourth digit. The fifth digit was not salvageable and had to be amputated. On arrival at the University of Alberta hospital (Edmonton, Alberta), a large amount of hematoma and necrotic tissue was noted on both surfaces of the hand. Contracture of the hand and fingers was apparent but there were no obvious signs of infection or cellulitis.

Following further debridement, the extensor and flexor tendons of the third digit were found to be exposed, along with portions of the metacarpal (Figures 1 and 2). The neurovascular bundles were also exposed (although intact) and satisfactory capillary refill was noted in all remaining digits. Definitive coverage was delayed due to Staphylococcus and Pseudomonas infections of the injured hand, which were dealt with using appropriate antibiotics and frequent changes of the Acticoat (Smith \& Nephew, Canada) dressing.

A vacuum-assisted closure dressing was applied in the hope of stimulating the growth of granulation tissue as coverage

Faculty of Medicine and Dentistry, University of Alberta, Edmonton, Alberta

Correspondence and reprints: Dr Jaret Olson, Division of Pediatric and Plastic Surgery, Department of Surgery, Faculty of Medicine and Dentistry, 2D3.78 WC Mackenzie Health Sciences Centre, 8840-112 Street, Edmonton, Alberta T6G 2B7. Telephone 780-407-8108,

fax 780-407-8131, e-mail jolson@cha.ab.ca 


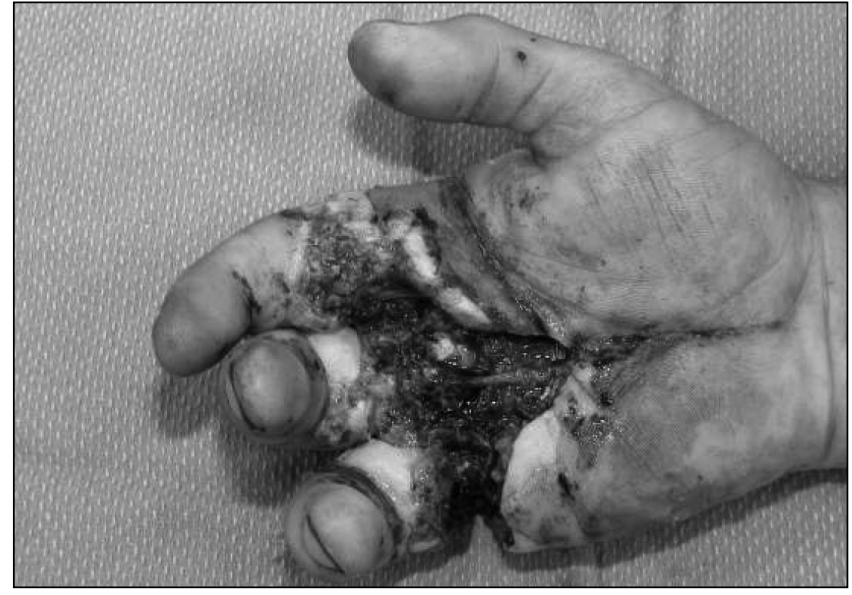

Figure 1) Volar aspect of degloved right hand before surgery

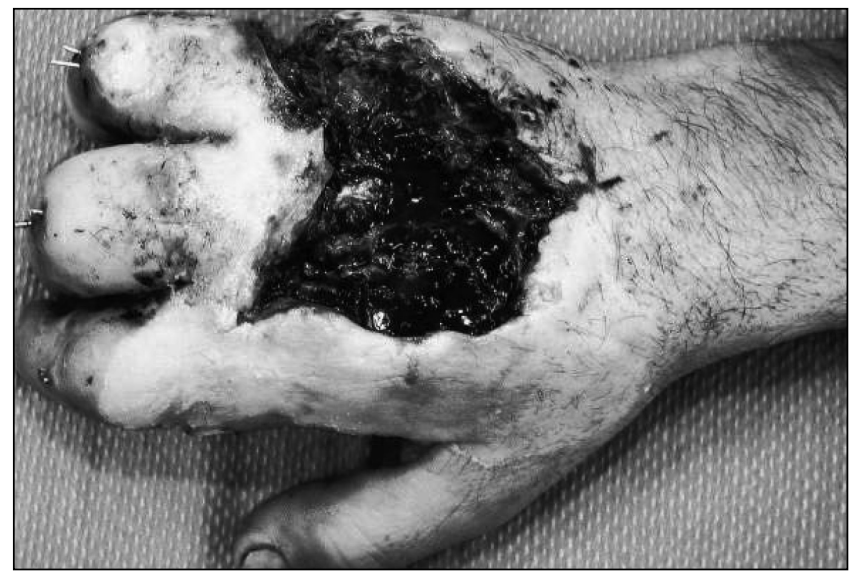

Figure 2) Dorsal aspect of degloved right hand before surgery

over the areas of exposed bone and tendon, and although there was some benefit, full coverage of the defect was not achieved. In an attempt to adequately cover both surfaces of the right hand, a bilobed pedicled groin flap was designed (Figure 3).

\section{METHODS}

The groin flap was raised from distal to proximal, elevating the skin and subcutaneous tissue down to the level of the fascia (Figure 4). Once the lateral border of the sartorius was encountered, the flap was thickened to include the fascia and the dissection was carried on to the medial portion of the sartorius. It is important to note that the axial pattern of the superficial circumflex iliac artery is only constant medial to the anterior superior iliac spine. For areas lateral to the anterior superior iliac spine, a random pattern flap is required and thus a strict 1:1 length to width ratio must be adhered to. The flap was fashioned into a tube proximal to the bilobed area, and good vascularity was evident in both lobes of the pedicle. The hand was transferred to the ipsilateral groin where flaps were inset onto both the volar (Figure 5) and dorsal (Figure 6) defects of the hand. A split thickness skin graft was harvested from the right thigh and used to cover the portions of the wounds that were left uncovered by the groin flap. The wound was then dressed with Xeroform (Sherwood Medical Industries Ltd, Canada) dry gauze and burn gauze, and affixed with

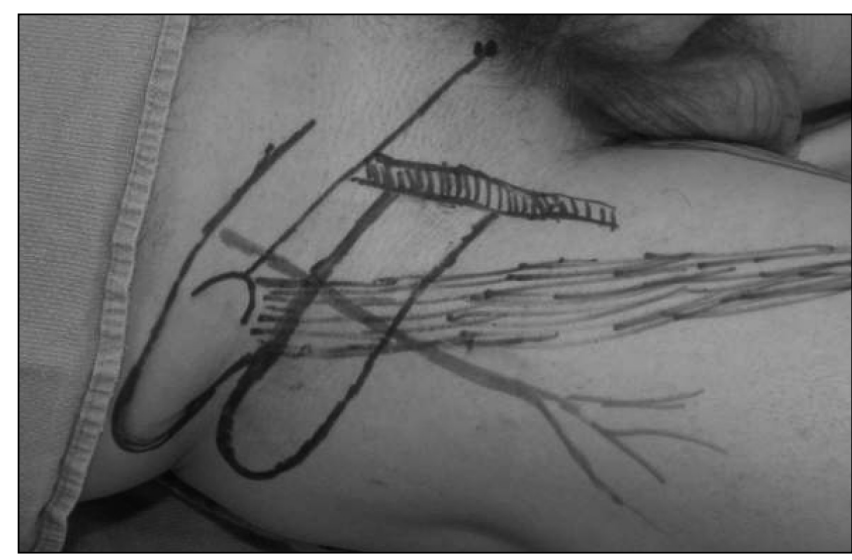

Figure 3) Markings for bilobed groin flap

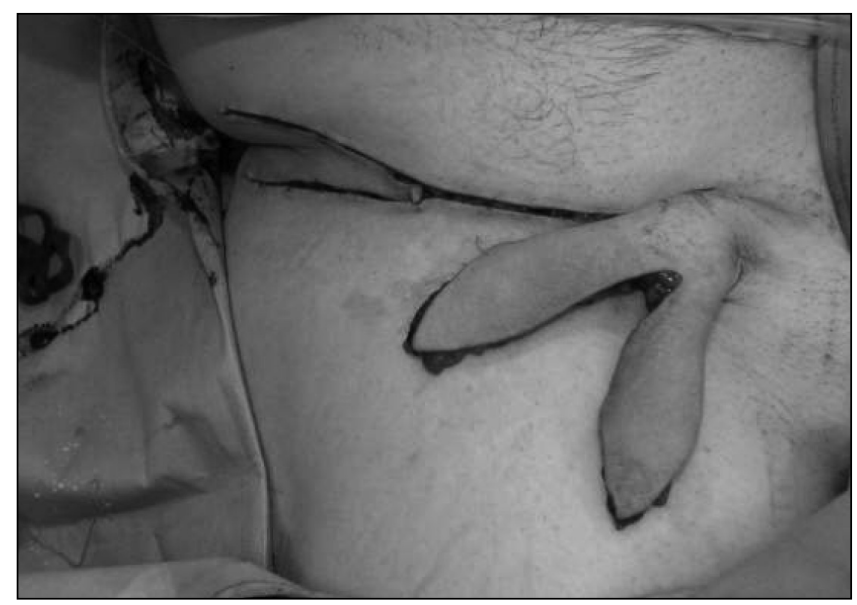

Figure 4) Elevated bilobed groin flap

Mefix tape (Molnlycke Health Care, USA). A sling and swath was then applied to reduce traction on the pedicle, while still allowing joint movement to prevent stiffness. The donor site was closed primarily without complication. Good position and colour of both flap insets was noted at the conclusion of the procedure.

The patient regained adequate hand function, and was able to return to his job as a manual labourer (Figure 7).

\section{DISCUSSION}

For years, hand surgeons have faced the challenge of dealing with concurrent traumatic injury of the dorsal and volar aspects of the hand. A good surgical technique for dealing with these complex injuries necessitates an adequate functional and cosmetic result of both the donor and recipient site as well as providing ample coverage to all of the vital structures (7). We believe that the bilobed groin flap surgery described above meets all of these criteria and has the added benefit of a single donor site, as opposed to the two flap systems utilized by other procedures.

The pedicled groin flap has long been accepted as a safe, easy and reliable option for the reconstruction of soft tissue defects (11). Because of these qualities, the pedicled flap remains widely used despite the current trend toward free tissue transfer flaps. The versatility of this flap can be further increased by raising it in a bilobed fashion. This allows the flap to wrap around a 


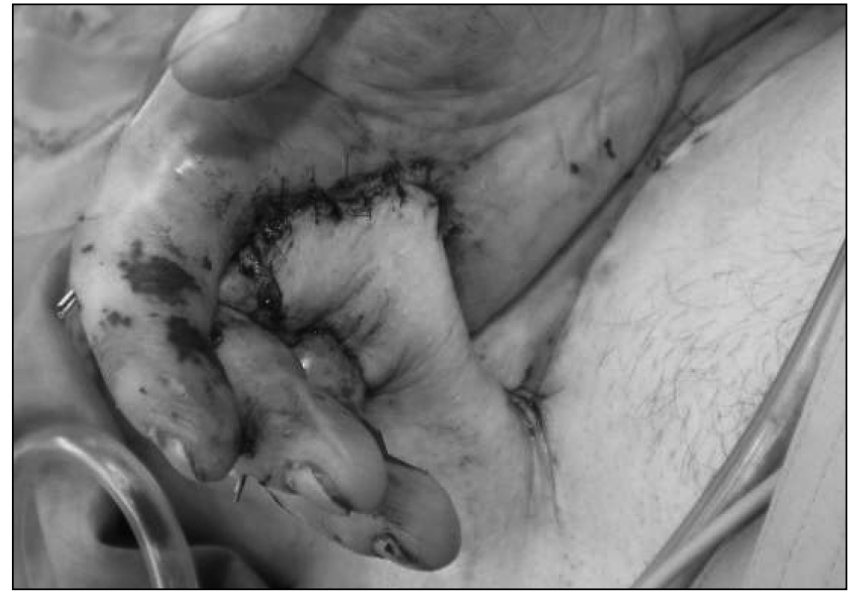

Figure 5) Bilobed flap insert on dorsal aspect of degloved hand

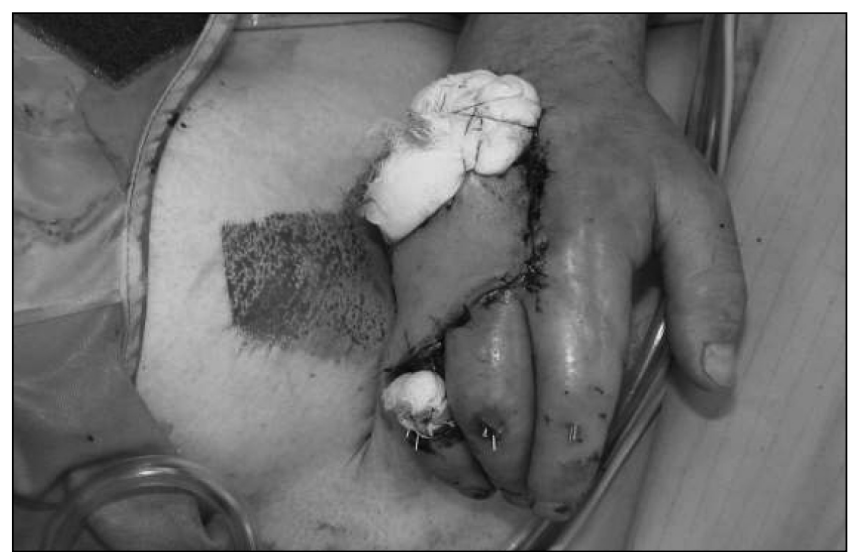

Figure 6) Bilobed flap insert on volar aspect of degloved hand

hand defect, thereby covering two surfaces without the need for a combined flap. This technique has been described in congenital hand deformities and in surgical release of thumb contractures, but this is the first report that we are aware of which uses this procedure in traumatic reconstruction. With simultaneous coverage of both surfaces of the hand, this single flap is simpler and more efficient than many of the combined flaps presented to date. This technique is a valuable option for dealing with traumatic, complex hand injuries.

\section{REFERENCES}

1. McGregor IA, Jackson IT. The groin flap. Br J Plast Surg 1972;25:3-16.

2. Arner M, Moller K. Morbidity of the pedicled groin flap. A retrospective study of 44 cases. Scand J Plast Reconstr Surg Hand Surg 1994;28:143-6.
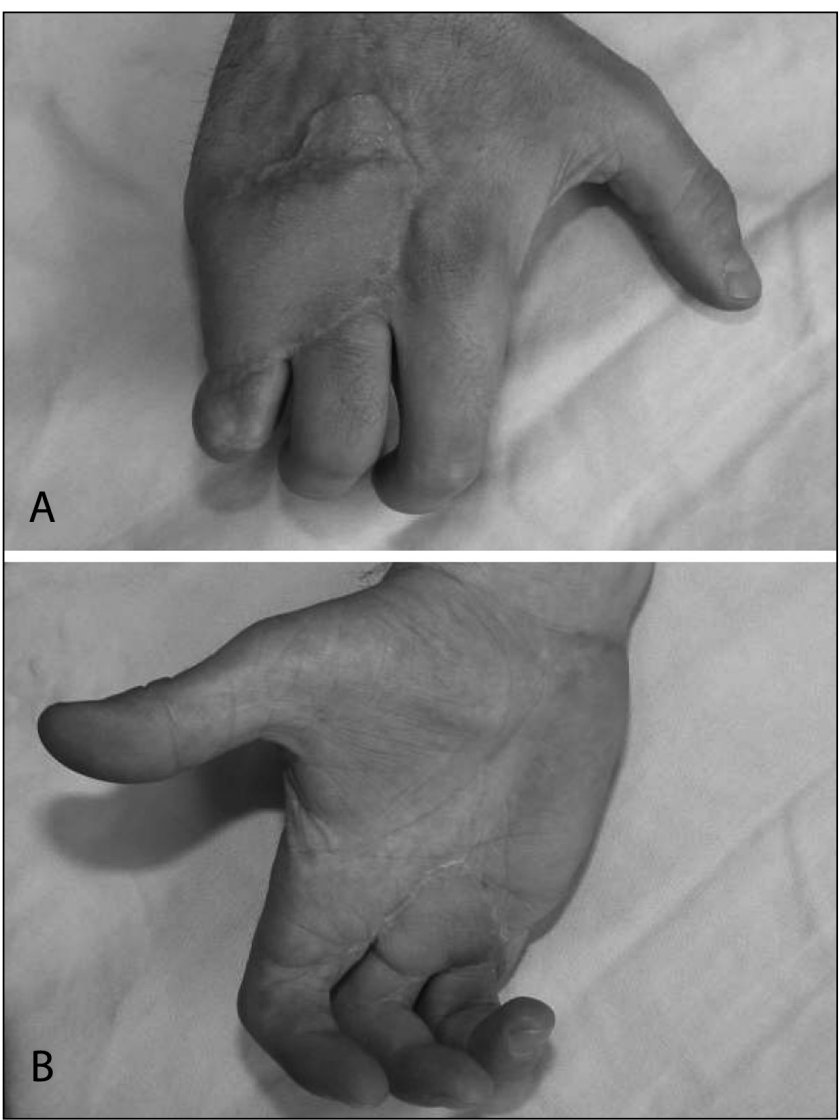

Figure 7) Results one year post surgery

3. Buchman SJ, Eglseder WA, Robertson BC. Pedicled groin flaps for upper-extremity reconstruction in the elderly: A report of 4 cases. Arch Phys Med Rehabil 2002;83:850-4.

4. Inigo F, Jimenez-Murat Y, Arroyo O, Martinez BA, Ysunza A. Free flaps for head and neck reconstruction in non-oncological patients: Experience of 200 cases. Microsurgery 2000;20:186-92.

5. Hough M, Fenn C, Kay SP. The use of free groin flaps in children. Plast Reconstr Surg 2004;113:1161-6.

6. Barfred T. The Shaw abdominal flap. Scand J Plast Reconstr Surg 1976;10:56-8.

7. Koncilia HF, Worseg AP, Kuzbari R, Holle J. The combined use of a pedicled Scarpa's fascia flap and a groin flap for simultaneous coverage of dorsal and palmar finger defects. J Hand Surg [Br] 1997;22:620-2.

8. Watson AC, Mcgregor JC. The simultaneous use of a groin flap and a tensor fasciae latae myocutaneous flap to provide tissue cover for a completely degloved hand. Br J Plast Surg 1981;34:349-52.

9. Zuker RM, Cleland HJ, Haswell T. Syndactyly correction of the hand in Apert syndrome. Clin Plast Surg 1991;18:357-64.

10. Climo MS. Split groin flap. Ann Plast Surg 1978;1:489-92.

11. Chuang DC, Colony LH, Chen HC, Wei FC. Groin flap design and versatility. Plast Reconstr Surg 1989;84:100-7. 